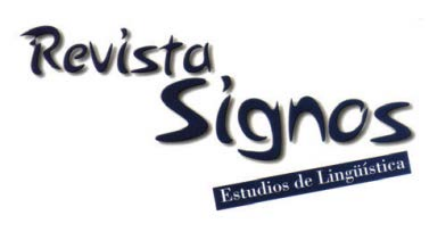

\title{
Malabarísticos e incuadrables: Sobre algunos procesos poco frecuentes en la formación neológica adjetiva ${ }^{1}$
}

\author{
Malabarísticos and incuadrables: On some non-frequent \\ neological processes for the formation of new adjectives
}

\author{
Miguel Sánchez Ibáñez \\ UNIVERSIDAD EUROPEA DEL ATLÁNTICO \\ NeOUSAL (Universidad DE SALAmanca) \\ ESPAÑA \\ miguelsanchez@usal.es
}

Recibido: 19-XI-2015 / Aceptado: 21-VII-2017

\section{Resumen}

Tradicionalmente, la neología adjetival se ha considerado como un conjunto de procesos morfológicos estables desde un punto de vista formal y semántico que generaba unidades de significado y estructura fácilmente predecibles. Sin embargo, no es difícil encontrar neologismos adjetivales que pongan en entredicho esa supuesta estabilidad. A partir de un corpus compuesto por textos periodísticos redactados durante cinco años en un contexto geográfico concreto (Castilla y León, España), este artículo analiza un conjunto de procesos de formación neológica adjetival, basados en la sufijación, la prefijación y la composición. La estructura formal y semántica de los neologismos adjetivales resultantes cuestiona los postulados tradicionales sobre formación de este tipo de unidades, al tiempo que pone de manifiesto la existencia de nuevos procesos de creación léxica. Por último, se sugieren una serie de causas que podrían estar detrás de la variedad de procesos reseñados.

Palabras Clave: Neología, adjetivos, sufijación, prefijación, composición. 


\begin{abstract}
Traditionally, adjectival neology has been envisioned as a group of stable morphological processes, from a formal and semantic point of view that generated meaning units and easily predictable structures. However, it is not difficult to find adjectives neologisms that question this supposed stability. Based on a corpus composed by journalist texts written up during five years in a concrete geographical context (Castilla y León, Spain), this article analyses a group of processes of adjectival neological formation, based in the suffixation, the prefixation, and the composition. The formal and semantic structure of the resulting adjectival neologisms question the traditional postulates about the formation of this type of units, at the same time that shows the existence of new processes of lexical creation. To conclude, a series of causes that may underlie the variety of reviewed processes are suggested.
\end{abstract}

Key Words: Neology, adjectives, suffixation, prefixation, compounding.

\title{
INTRODUCCIÓN
}

La manera en que el castellano desarrolla y articula nuevas estrategias de creación de adjetivos tiene un peso nada desdeñable en la actualización de su caudal léxico. Tradicionalmente, la neología adjetival se ha considerado como un conjunto de procesos morfológicos estables desde un punto de vista formal y semántico que originaba unidades de significado y estructura fácilmente predecibles. Sin embargo, y como veremos a continuación, no es difícil encontrar neologismos adjetivales que pongan en entredicho esa supuesta estabilidad.

La hipótesis que nos planteamos demostrar con este artículo es que existen procesos de creación de neologismos adjetivales que no tienen cabida dentro de las clasificaciones tradicionales, pero que, al mismo tiempo, poseen la entidad suficiente como para ser considerados como procesos neológicos de una recurrencia incipiente, que obligan a replantear qué tipo de unidades denominamos adjetivos y por qué. Nos proponemos, en consecuencia, un doble objetivo: por un lado, describimos los diferentes procesos de creación adjetival empleados en un corpus determinado (formado por una muestra de prensa escrita de la región de Castilla y León, en España) durante un periodo de tiempo en particular (2009-2014). Por el otro, detectamos y clasificamos, al menos de manera preliminar, las combinaciones poco frecuentes entre los distintos procesos morfológicos y significados que se dan en el conjunto de unidades estudiadas y que, sin embargo, presentan una entidad suficiente como para que se tengan en cuenta. Para llevar esto a cabo, hemos seguido una metodología que se divide en dos fases: en la primera de ellas nos hemos basado en la aplicación del criterio de exclusión lexicográfica a las unidades que constituyen nuestro corpus de trabajo y en la clasificación de los neologismos resultantes de acuerdo con su categoría gramatical y con los procesos de creación neológica que los han generado. En la segunda fase nos hemos centrado en el análisis detallado de las unidades clasificadas como adjetivas. 
El artículo se organiza en torno a un marco teórico, una descripción de la metodología adoptada y una explicación de las particularidades detectadas en los neologismos adjetivales estudiados, según su procedimiento de formación (sufijación, prefijación y composición). Para finalizar, apuntamos algunas conclusiones extraídas de nuestro análisis.

\section{Marco teórico}

La renovación léxica de un código lingüístico es una cuestión sobre la que han disertado diversos autores (Guilbert, 1975; Rey, 1976; Cabré, 2000; Sablayrolles, 2009, 2010; Boulanger, 2010). Se trata de un fenómeno necesario "para la evolución de las lenguas y su adaptación a las nuevas realidades a las que hacer referencia, con una dimensión social y temporal" (Vallès, 2002: 150). La neología define un punto de tensión en el plano superficial de un código, entre el peso del elemento diacrónico, que aboca al lenguaje a su estabilización, y el de la pulsión sincrónica por regenerar su sustrato léxico (Guilbert, 1975; Cabré, 2000; Álvarez Català, 2010). Algunos factores que relativizan esa tensión pueden ser los mencionados por Quirion (2010) a propósito del éxito de la implantación de los neologismos; la ausencia de sinonimia, la productividad morfológica (tienen más éxito las unidades productivas), la concisión y la adecuación a las normas del código favorecen la pervivencia y asentamiento de las nuevas unidades dentro de un código.

Los neologismos adjetivales en castellano se han considerado, tradicionalmente, como unidades que se podían enmarcar en las premisas de Quirion (2010) y seguían procesos de formación predecibles: Demonte, (en Bosque \& Demonte, 1999) habla de determinados significados que se articulan 'preferentemente' mediante la creación de este tipo de unidades y que, en consecuencia, "establecen relaciones semánticas determinadas" (Bosque \& Demonte, 1999: 150), y no es complicado encontrar estudios morfológicos que se refieran a la sufijación como el proceso más común para crear adjetivos, con gran variedad de clasificaciones que estipulan y documentan la estabilidad semántica de los sufijos, y el tipo de adjetivos que resultan de la afijación de estos (Lang, 1992; Pena, 2001; Varela Ortega, 2005; Casado-Velarde, 2015). En consecuencia, podríamos decir que la mencionada tensión entre estabilización y renovación se ve relativizada si hablamos de neología adjetival. Sin embargo, y a pesar de la aparente sistematización y claridad en los procesos morfológicos que dan como resultado adjetivos, existen otras dimensiones de análisis de este tipo de palabras que apenas han sido estudiadas, como el nivel sintáctico, el pragmático, o las relaciones que se establecen entre ambos y con el plano morfológico (Moreno Benítez, 2010). La manera en que los adjetivos terminan por articularse en un contexto determinado, especialmente si son de reciente acuñación, pasa por la imbricación de todas esas dimensiones (semántica, morfológica, pragmática), lo que muchas veces da resultados léxicos dispares y difícilmente clasificables. La formación de palabras no consiste únicamente en unir piezas disponibles, sino que intervienen aspectos lingüísticos muy 
variados (Serrano Dolader, 2012). Existen fenómenos como las "transgresiones semánticas, pragmáticas o por analogía”, trabajados por Freixa (2010: 14), que tienen lugar en los procesos de formación de adjetivos y que dan como resultado lo que esta autora denomina paraules amb raresses, es decir, unidades que se salen de lo esperable. Incluso Varela Ortega (2005: 33), que aporta una detallada descripción de los patrones más prototípicos de creación adjetival, recuerda que:

"[la derivación] no constituye un proceso totalmente productivo ni automático: ni todas las derivaciones posibles se actualizan en la lengua, ni las pautas derivativas que se aplican a unas formaciones son extensivas a todas las de su clase".

Las relaciones entre las dimensiones morfológica y semántica, que son las que nos ocupan principalmente en este artículo, son especialmente variables, tal y como demuestran los ejemplos que vamos a detallar. Rainer (2003), con su trabajo sobre la representación sincrónica de patrones polisémicos o con su concepto de fragmentación semántica (Rainer, 2010), plantea varias vías, a caballo entre ambas dimensiones, que pueden ayudarnos a enmarcar los casos que vamos a detallar.

“Tradicionalmente se pensaba que el cambio semántico de los patrones lexicogenésicos era una consecuencia del cambio semántico de alguna(s) palabra(s) compleja(s): alguna(s) de las palabras complejas usuales sufría(n) un cambio semántico, del tipo conocido del ámbito de las palabras simples, y la(s) nueva(s) palabra(s) resultante(s) de este cambio se tomaba(n) luego como punto de partida para formaciones analógicas, dando lugar así a un nuevo patrón." (Rainer, 2010: 21).

En definitiva, nuestro análisis plantea nuevas vías para la observación y la posterior clasificación de los procesos de creación de adjetivos. Para ello tomamos como punto de partida la tensión que produce la neología en los códigos y la variedad de resultados que pueden generar las combinaciones novedosas de los planos morfológico y semántico al confluir en unidades de nuevo cuño.

\section{Marco metodológico}

Para obtener los resultados que analizamos en este artículo, hemos desarrollado una metodología claramente diferenciada en dos partes: en primer lugar, hemos clasificado un conjunto de neologismos extraídos de la prensa escrita y, en segundo lugar, nos hemos centrado en mayor detalle, dentro de esas unidades, en aquellas que tenían una naturaleza adjetival. Ambas fases se desarrollaron en el Observatorio de Neología de la Universidad de Salamanca (NeoUSAL), miembro de la red NEOROC de Observatorios de Neología, coordinada desde el Institut Universitari de Lingüistica Aplicada (IULA), en la Universitat Pompeu Fabra, que estudia la neología de la región española de Castilla y León. En la primera fase, clasificamos los neologismos extraídos de manera semiautomática de un corpus compuesto por dos números mensuales 
escogidos de manera aleatoria de diez periódicos publicados en Castilla y León ${ }^{2}$ entre los años 2009 y 2014. La extracción de las unidades siguió la metodología y directrices marcadas desde el IULA, comunes a todos los observatorios de la red (OBNEO, 2004). Dicha extracción tuvo como principal base metodológica la aplicación de un criterio de exclusión lexicográfica, que consiste en detectar la presencia de una determinada unidad en un corpus de exclusión compuesto por diccionarios representativos de una lengua dada (Nazar \& Vidal, 2008) y, en el caso de no encontrarla, considerarla como neologismo.

En nuestro caso, el corpus de exclusión estuvo compuesto por dos diccionarios, que, de acuerdo con lo que establece el OBNEO en sus directrices (OBNEO, 2004) fueron el Diccionario de la Lengua Española, (Real Academia Española, 2001) y el LEMA: Diccionario de la Lengua Española (Battaner, 2001). Este primer paso metodológico nos permitió obtener un conjunto de unidades novedosas de acuerdo con un criterio fácilmente objetivable. Sin embargo, y tal y como advierten Nazar y Vidal (2008), muchos de los candidatos a neologismo (unidades no recogidas en los diccionarios del corpus de exclusión) distan de lo que el hablante de una lengua percibe como palabra nueva, ya que se pueden ver incluidas unidades que hacen referencia a "tecnicismos o distintas entidades del mundo" (Nazar \& Vidal, 2008: 1) y, a su vez, excluir la neología sintagmática o la semántica. Con todo, y a pesar de estas limitaciones, obtuvimos un total de 4.989 unidades no recogidas en los diccionarios mencionados, esto es, susceptibles de poder ser consideradas como neologismos lexicográficos. Con el fin de paliar parte de las limitaciones apuntadas por Nazar y Vidal (2008), y para determinar qué unidades de las seleccionadas podían considerarse como 'nuevas', partimos de la noción de sentimiento neológico (es decir, del nivel de percepción de una unidad como novedosa por parte de sus usuarios) planteada por Guespin (1974), y por Bardin, Lefevère, Marcellesi y Mortureux (1974), quienes plantearon por primera vez de manera específica el peso de ese sentimiento en la configuración de los neologismos, ligándolo al discurso en el que dichas unidades se insertan y dando protagonismo a la metaforización como procedimiento neologizador más evidente.

Más recientemente, Sablayrolles (2010) ha dado un paso más en la definición de dicho sentimiento, al estipular que, si existe concurrencia de varias unidades para denominar una misma realidad, si en los contextos de uso aparecen aposiciones de sinónimos o contextos definitorios, o si aparecen recursos tipográficos que pretenden poner de manifiesto la novedad de la unidad, la probabilidad de que nos encontremos frente a un neologismo aumenta. Tras haber comprobado todos esos factores de manera manual, así como la categoría gramatical de cada una de las unidades, terminamos seleccionando 1.666 neologismos con valor adjetival (un 34\% del total). En ese punto dio comienzo la segunda fase de nuestro estudio, en la que analizamos en mayor detalle otras cuestiones relativas a ese subconjunto de neologismos, como su 
proceso de formación o la presencia de marcas tipográficas en cada uno de los contextos en los que aparecieron.

Hubo dos hechos que nos llamaron la atención:

- La gran variedad de procesos neológicos documentados.

- La existencia de varios casos de unidades formadas mediante el mismo proceso morfológico que, sin embargo, daban como resultado unidades semánticamente muy diversas.

Es necesario tener en cuenta que los datos que presentamos han sido extraídos de textos pertenecientes al discurso periodístico, publicados en un canal en concreto (el escrito) y en un ámbito muy determinado (prensa escrita castellanoleonesa), lo que también relativiza las conclusiones extraídas y limita su alcance. Con todo, consideramos que la sistematicidad del trabajo realizado, su extensión a lo largo de un periodo de tiempo prolongado (2009-2014) y la cantidad de ejemplos de uso real detectados hacen que este análisis pueda tomarse como una 'fotografía' de un hecho lingüístico concreto, pertinente para apuntar algunas claves que hagan replantear los procesos morfológicos que se emplean para acuñar nuevos adjetivos.

\section{Resultados}

\subsection{Análisis de los neologismos adjetivales encontrados, según su proceso de formación}

En las 1.666 unidades neológicas marcadas como 'adjetivos', hemos encontrado los procesos de creación de palabras recogidos en la Tabla 1. Hemos decidido centrarnos en la sufijación, la prefijación y la composición para hacer nuestro análisis. Esta limitación viene marcada por el objetivo de no alargar demasiado el artículo que presentamos y convertirlo en un estudio excesivamente general. Del mismo modo, y como veremos, los tres procesos de creación de palabras en los que nos vamos a centrar nos permiten analizar casos que, si bien no aparecen en el corpus con excesiva frecuencia, son lo suficientemente recurrentes como para poder extraer conclusiones. 
Tabla 1. Neologismos adjetivos por el grupo NeoUSAL (2009-2014), según su proceso de formación.

\begin{tabular}{|c|c|c|c|c|c|}
\hline Proceso & \begin{tabular}{|l|}
$\begin{array}{l}\text { Numero de } \\
\text { ocurrencias }\end{array}$ \\
\end{tabular} & $\begin{array}{c}\text { Porcentaje } \\
\text { del total }\end{array}$ & Ejemplo & Periódico & Fecha \\
\hline Sufijación & 872 & $51,8 \%$ & $\begin{array}{l}\text { Las entidades colocadoras } \\
\text { son Citi, UBS y BEKA } \\
\text { Finance. }\end{array}$ & $\begin{array}{l}\text { El Norte } \\
\text { de Castilla }\end{array}$ & $10 / 04 / 2014$ \\
\hline Prefijación & 325 & $19,50 \%$ & $\begin{array}{l}\text { Un grupo de } 300 \\
\text { manifestantes } \\
\text { progubernamentales atacó } \\
\text { con piedras }(. . .) \text { a un millar } \\
\text { de activistas. }\end{array}$ & $\begin{array}{l}\text { La } \\
\text { Opinión } \\
\text { de } \\
\text { Zamora }\end{array}$ & $21 / 02 / 2011$ \\
\hline $\begin{array}{l}\text { Composición } \\
\text {-Patrimonial: } \\
103 \\
\text {-Cultura: } 178\end{array}$ & 281 & $17,30 \%$ & $\begin{array}{l}\text { El día 25, César Sanz, } \\
\text { secretario de Galehi } \\
\text { intervendrá para hablar de } \\
\text { las familias homoparentales } \\
\text { y la educación. }\end{array}$ & $\begin{array}{l}\text { Diario de } \\
\text { Ávila }\end{array}$ & $21 / 06 / 2009$ \\
\hline $\begin{array}{l}\text { Préstamos de } \\
\text { otras lenguas }\end{array}$ & 131 & $7,80 \%$ & $\begin{array}{l}\text { En cuanto a la oferta low- } \\
\text { cost, el aeropuerto de } \\
\text { Valladolid es el único que } \\
\text { cuenta con compañías de } \\
\text { este tipo. }\end{array}$ & $\begin{array}{l}\text { Diario de } \\
\text { Burgos }\end{array}$ & $01 / 04 / 2014$ \\
\hline $\begin{array}{l}\text { Otros } \\
\text { mecanismos } \\
\text { (conversión, } \\
\text { lexicalización, } \\
\text { acronimia...) }\end{array}$ & 57 & $3,40 \%$ & $\begin{array}{l}\text { No es de extrañar que Hiba } \\
\text { se decante por este estilo, } \\
\text { pues ella misma se describe } \\
\text { como flamencólica en su } \\
\text { cuenta de Twitter. }\end{array}$ & $\begin{array}{l}\text { La } \\
\text { Opinión } \\
\text { de } \\
\text { Zamora }\end{array}$ & $01 / 04 / 2014$ \\
\hline
\end{tabular}

\subsection{Sufijación}

Los neologismos adjetivales formados por sufijación constituyen el grupo más numeroso de entre los estudiados $(51,8 \%)$. En consecuencia, no resulta extraño comprobar que es también el más diverso, tanto desde el punto de vista temático como atendiendo a la variedad de formantes que encontramos, como muestra la Tabla 2: 
Tabla 2. Neologismos adjetivales formados por sufijación.

\begin{tabular}{|c|c|c|c|c|c|}
\hline Relativo a & $\begin{array}{l}\text { Numero de } \\
\text { ocurrencias }\end{array}$ & $\begin{array}{c}\text { Porcentaje } \\
\text { del total }\end{array}$ & Ejemplo & Periódico & Fecha \\
\hline $\begin{array}{l}\text { Entidades } \\
\text { geográficas }\end{array}$ & 503 & $57,6 \%$ & $\begin{array}{l}\text { Al Consistorio carrionés no } \\
\text { le ha quedado más remedio } \\
\text { que tomar este acuerdo de } \\
\text { inicio de expediente. }\end{array}$ & $\begin{array}{l}\text { Diario } \\
\text { Palentino }\end{array}$ & $1 / 9 / 2012$ \\
\hline $\begin{array}{l}\text { Entidades } \\
\text { deportivas }\end{array}$ & 47 & $5,3 \%$ & $\begin{array}{lrr}\text { El primer } & \text { tiempo fue } \\
\text { calcado al Xerez-Racing }(. . .) \\
\text { con un } & \text { comienzo } \\
\text { apabullante } & \text { del } & \text { equipo } \\
\text { xerecista y un } & \text { posterior } \\
\text { dominio } & \text { del } & \text { cuadro } \\
\text { visitante. } & & \end{array}$ & $\begin{array}{l}\text { El Norte } \\
\text { de Castilla }\end{array}$ & $1 / 5 / 2010$ \\
\hline $\begin{array}{l}\text { Nombres } \\
\text { de persona }\end{array}$ & 40 & $4,6 \%$ & $\begin{array}{l}\text { Yo soy una persona chavista } \\
(\ldots) \text {, pero no estoy ni tengo } \\
\text { interés de estar en la política } \\
\text { activa. }\end{array}$ & $\begin{array}{l}\text { Diario de } \\
\text { Ávila }\end{array}$ & $11 / 7 / 2011$ \\
\hline Otros & 282 & $32,3 \%$ & $\begin{array}{l}\text { Remontar era sólo una } \\
\text { quimera, pero, cuando } \\
\text { menos, querían evitar que la } \\
\text { derrota fuese más } \\
\text { sonrojante. }\end{array}$ & $\begin{array}{l}\text { Diario } \\
\text { Palentino }\end{array}$ & $1 / 1 / 2014$ \\
\hline
\end{tabular}

Torijano y Sánchez Ibáñez (2013) detallaron la falta de sistematicidad, la creatividad y la variación semántica resultante de sufijar distintos formantes a bases léxicas relativas a entidades geográficas, deportivas y relativas a nombres de persona en un estudio basado en un corpus similar al empleado en este análisis. Por ese motivo, hemos decidido dejar esas unidades a un lado en este análisis. Además, y a pesar de que hubieran superado el criterio de exclusión lexicográfica en la primera fase de nuestro trabajo, pertenecen a ese tipo de palabras que "distan de lo que el hablante de una lengua percibe como palabra nueva" (Nazar \& Vidal, 2008: 1). Por otra parte, los procedimientos de formación eran, por norma general, recurrentes y predecibles, así que no se correspondían con el objeto de nuestro análisis. Por este motivo, nos hemos centrado en las 282 unidades que no se podían incluir en estas tres categorías, en las que hemos detectado los siguientes procesos de creación neológica poco frecuentes:

\subsubsection{Adjetivos sufijados en - ble con base nominal}

Un grupo de adjetivos formados por sufijación que resultó ser numeroso (44 de los 282 compilados, un 15,6\%) fue el compuesto por unidades a las que se les había afijado el morfema '-ble'. Observamos a continuación algunos de los ejemplos recopilados:

(1) 'El entrenador de la Real Sociedad Martín, Lasarte, destacó tras el partido que el triunfo no será fácilmente olvidable para él.' (La Opinión de Zamora, 1/5/2011) 
(2) 'Cada perro tiene una puntuación del 1 al 10 en función de si son paseables o no.' (Diario de Burgos, 11/8/2014)

Se trata de uno de los mecanismos más productivos y predecibles, que genera adjetivos deverbales con un significado inequívoco: los adjetivos formados mediante la adición de este sufijo denotan la capacidad de poder realizar la acción expresada por los verbos de los que se derivan (descargable, 'que se puede descargar'; olvidable, 'que se puede olvidar', etc.) Diversos autores (de Miguel, 1986; Kornfeld, 2014) hacen referencia a la estabilidad de este patrón de formación neológica, por lo que a priori no debería tener especial relevancia en nuestro estudio. Sin embargo, hemos encontrado un caso no deverbal en el que consideramos pertinente detenernos:

(3) 'Pero mientras las urnas allanaron el camino a algunos, sellaron un destino más sombrío para otros candidatos presidenciables.' (Diario de Ávila, 1/7/2009)

A pesar de poder inferir un hipotético verbo 'presidenciar', la realidad es que el verbo que se usa es 'presidir', que derivaría en 'presidible'. Es más, incluso aceptando que pudiera existir un hipotético 'presidenciar' (resultado de un proceso similar al que tiene lugar en 'influir/influenciar'), este caso se seguiría saliendo de la norma por motivos semánticos, puesto que un 'presidenciable' no es alguien que puede ser 'presidido' (o 'presidenciado'), sino un candidato a ser presidente.

\subsubsection{Sufijación en -(íst)ico/-(íst)ica como marca de registro}

En el caso de los neologismos adjetivales formados por la afijación del sufijo (ist)ico/-(ist)ica (20 ocurrencias, un 7\% de los 282 analizados en este apartado) vemos indicios de que el significado de las unidades resultantes las resitúa (o pretende resituar) en un registro de uso más elevado que el de las bases léxicas desde las que se derivan. La relación de los adjetivos de este tipo, esencialmente relacionales, con registros de uso y ámbitos temáticos más especializados que los demás nos resultó llamativo desde el primer momento, con ejemplos como 'alelopático -ca', 'sofismático ca' o 'avifaunístico -ca'. Observamos una especificidad temática bastante clara e incluso, en algunos casos, una glosa explicativa que sugeriría que los destinatarios medios del texto no tienen por qué entender su significado sin ayuda. En la mayoría de los 20 adjetivos recogidos en este apartado, estos rasgos parecen claros e inequívocos. Sin embargo, un 15\% de los casos (3, en términos absolutos) presentan ciertos puntos en común que se salen de la tendencia marcada, como podemos observar en la Tabla 3: 
Tabla 3. Neologismos adjetivales en -(íst)ico/-(íst)ica.

\begin{tabular}{|l|l|l|l|}
\hline \multicolumn{1}{|c|}{ Neologismo } & \multicolumn{1}{|c|}{ Contexto } & \multicolumn{1}{c|}{ Fuente } & \multicolumn{1}{c|}{ Fecha } \\
\hline Ornamentístico, -ca & $\begin{array}{l}\text { (..) se caracteriza por el uso de flores y } \\
\text { elementos ornamentísticos. }\end{array}$ & $\begin{array}{l}\text { El Norte de } \\
\text { Castilla }\end{array}$ & $1 / 12 / 2011$ \\
\hline Matérico, -ca & $\begin{array}{l}\text { unos fondos que con el tiempo han adquirido } \\
\text { una textura más matérica. }\end{array}$ & Diario de León & $1 / 10 / 2012$ \\
\hline Malabarístico, -ca & $\begin{array}{l}\text { El broche de oro se pondrá el domingo } \\
\text { con(...) las olimpiadas malabarísticas }\end{array}$ & $\begin{array}{l}\text { Diario } \\
\text { Palentino }\end{array}$ & $1 / 10 / 2009$ \\
\hline
\end{tabular}

La base sobre la que se afijan no parece, a priori, excesivamente especializada y existen adjetivos totalmente asentados para todos los casos, como vemos en la Tabla 4. La afijación de este formante en estos casos provoca la aparición de dobletes que, atendiendo al resto de neologismos adjetivales recopilados en este apartado, bien podría responder a una intención de especialización temática, de elevación del registro de uso o, como dicen Berri y Borhn (2009) de aportar cierto toque de estilo. En definitiva, de acuerdo con los datos recopilados, nos encontramos frente a un caso en el que la sufijación implica una especialización (o 'fragmentación', según el planteamiento de Rainer, 2010) semántica. Dicha especialización marca, más que un nuevo matiz de significado, una adecuación de las unidades a un registro de uso más formal que el de las unidades ya existentes, como vemos en la Tabla 4:

Tabla 4. Variantes del DRAE para los neologismos adjetivales acabados en '- (íst)ico/ (íst)ica'.

\begin{tabular}{|l|l|l|l|}
\hline $\begin{array}{c}\text { Sustantivo } \\
\text { base }\end{array}$ & \multicolumn{1}{|c|}{$\begin{array}{c}\text { Adjetivo } \\
\text { existente }\end{array}$} & \multicolumn{1}{|c|}{ Def. DRAE } & $\begin{array}{c}\text { Neologismo adjetival } \\
\text { detectado }\end{array}$ \\
\hline Malabar & Malabar & Natural de Malabar V.juegos malabares & Malabarístico -ca \\
\hline Ornamento & Ornamental & $\begin{array}{l}\text { Perteneciente o relativo a la } \\
\text { ornamentación o adorno. }\end{array}$ & Ornamentístico -ca \\
\hline Materia & Material & Perteneciente o relativo a la materia. & Matérico -ca \\
\hline
\end{tabular}

\subsubsection{Sufijo -ero/-era como marca eventiva}

Hemos encontrado 34 adjetivos acabados con este sufijo, un 12\% de los 282 estudiados en este apartado. Normalmente, este tipo de adjetivos han sido utilizados para designar profesiones, y así lo confirman Casado Velarde (2015) o Varela Ortega (2005) al incluirlos en el apartado de 'sufijos nominales y adjetivales que indican oficios y ocupaciones'. Otras clasificaciones consultadas (Lang, 1992; Santana, Carreras, Pérez \& Rodríguez, 2003; Fuentes, Cañete, Gerding, Kotz \& Pecchi, 2010) remiten a otros significados, como lugares donde se guardan otros elementos, nombres de plantas o instrumentos, o seguidores de equipos deportivos. Hemos encontrado varios ejemplos en consonancia con estas clasificaciones, como 'pizarrero -ra' o 'tuitero -ra'. Sin embargo, 9 de los 34 adjetivos de este tipo detectados en nuestro análisis (un 26,4\%) no tienen cabida en esta clasificación y, por el contrario, 
presentan otro matiz de significado bastante definido. A continuación observamos tres de esos casos:

(4) 'los semanasanteros ilustres no quisieron perderse el acto.' (La Opinión de Zamora 21/8/2011)

(5) '(...) eligió Twitter como aliado para dar a conocer lo que se estaba cociendo en el espacio campusero.' (El Norte de Castilla, 11/7/2011)

(6) 'cuando se empezaron a retirar los coches que aún permanecían en el recinto pingüinero (...)’ (El Norte de Castilla, 11/1/2013)

A la vista de los contextos, nos aventuramos a marcar un nuevo matiz que, si bien no es del todo evidente, sí que resulta constante y, a nuestro juicio, tiene la entidad suficiente como para que se repare en él: en estos ejemplos los neologismos adjetivales derivan de sustantivos que denominan eventos, acontecimientos que se producen de manera periódica y con una duración determinada: la Semana Santa, un campus (entendido como concentración de aficionados a la informática) y los Pingüinos, concentración de moteros que tiene lugar anualmente en la región de Castilla y León. Tal y como afirman Fuentes et al. (2010: 72), a propósito de los nuevos usos de este sufijo, tiene lugar:

"una ruptura de la previsibilidad debido, fundamentalmente, a que algunas unidades han adquirido nuevos valores, a que se ha producido un cambio o una ampliación de sentido, o a que las unidades nuevas se perciben como distintas, raras o extrañas por parte del hablante".

Una vez más, comprobamos cómo un formante que tiene un significado ya establecido en la lengua sufre una resemantización para adecuarse a nuevas realidades y necesidades descriptivas.

\subsubsection{Algunos casos problemáticos}

Para concluir el apartado de neologismos adjetivales pocos frecuentes creados por sufijación incluimos en este último apartado algunos casos que, por falta de recurrencia en los matices de significado que denotan o por la poca claridad de los mismos, se acercan más al error o a la variación puntual que a un nuevo paradigma morfosemántico, como ocurría con los casos reseñados en los apartados anteriores:

(7) 'De las acciones combinativas de estos jugadores llegaron las mejores aproximaciones.' (Diario de Burgos, 1/04/2014)

(8) No les digo los nombres de los entrantes, los salientes y los intermedios por no hacer que sus glándulas salivares suelten más líquido que el hambruno perro de Pavlov.' (El Norte de Castilla, 11/12/2011) 
(9) 'Bien sea mediante publicidad o bien con declaraciones y comentarios aduladoras o descalificadoras en los medios.' (El Norte de Castilla, 10/4/2014)

En estos casos, la existencia de 'combinatorio -a', 'hambriento -a' y 'descalificativo -a', unida al carácter puntual que hemos mencionado y a la ausencia de un matiz semántico claramente diferenciado, nos hace dudar del éxito de la implantación de las unidades que vemos en los ejemplos. Con todo, resulta interesante comprobar hasta qué punto la analogía con otras unidades similares (el peso del sustantivo 'hambruna' resulta evidente, por ejemplo) comporta una creatividad léxica que, si bien es previsiblemente errónea o, al menos, redundante desde un punto de vista semántico, se inserta con toda naturalidad en el discurso y tiene un significado claro para cualquier hablante. Aunque hemos detectado un abanico de tipos de sufijación adjetival muy diverso, los aquí reseñados son los que confirmaban nuestra hipótesis de una manera más clara. Demuestran, en definitiva, que las irregularidades "en la relación semántica entre el primitivo y el derivado" (Varela Ortega, 2005: 33) son una vía notable para la creatividad léxica adjetival en el castellano actual.

\subsection{Prefijación}

Para analizar las variaciones detectadas en los adjetivos creados por prefijación (325 ocurrencias, un 19,5\% del total estudiado) hemos seguido un proceso similar al adoptado con los adjetivos creados mediante sufijación: en primer lugar, los hemos agrupado y clasificado atendiendo a criterios formales para, a continuación, intentar rastrear algún tipo de variación semántica en las unidades formalmente similares. La Tabla 5 recoge los prefijos detectados para crear adjetivos, ordenados según la clasificación propuesta por la Nueva Gramática de la Lengua Española (2009). 
Tabla 5. Prefijos detectados en el análisis, según su significado.

\begin{tabular}{|c|c|c|c|c|}
\hline & $\begin{array}{c}\text { Ocurrencias } \\
(\%)\end{array}$ & Prefijo & $\begin{array}{c}\mathrm{N}^{\mathrm{o}} \mathrm{de} \\
\text { ocurrencias }\end{array}$ & Ejemplo \\
\hline \multirow[t]{9}{*}{ Espaciales } & \multirow{9}{*}{$\begin{array}{l}72 \\
(22,1 \%)\end{array}$} & inter- & 37 & intercomarcal \\
\hline & & sub- & 19 & sub-21 \\
\hline & & intra- & 5 & intradiario -ria \\
\hline & & para- & 3 & parapolicial \\
\hline & & entre- & 2 & entreasado -da \\
\hline & & nor- & 2 & norcaucásico -ca \\
\hline & & trans- & 2 & transactivo -va \\
\hline & & meta- & 1 & metaliterario -ria \\
\hline & & supra- & 1 & supra-30 \\
\hline \multirow[t]{3}{*}{ Temporales } & \multirow{3}{*}{$\begin{array}{l}35 \\
(10,7 \%)\end{array}$} & post- /pos- & 15 & postguardia \\
\hline & & pre- & 15 & predinástico -ca \\
\hline & & neo- & 5 & neomudéjar \\
\hline \multirow[t]{9}{*}{ Cuantitativos } & \multirow{9}{*}{$\begin{array}{l}77 \\
(23,6 \%)\end{array}$} & multi- & 29 & multifase \\
\hline & & semi- & 23 & semiperpetuo -tua \\
\hline & & extra & 9 & extraurbano -na \\
\hline & & bi- & 5 & bipulmonar \\
\hline & & pan- & 5 & pancatalanista \\
\hline & & pluri- & 3 & pluripatológico -ca \\
\hline & & mono- & 1 & monovarietal \\
\hline & & poli- & 1 & polimedicado -da \\
\hline & & tri- & 1 & trianual \\
\hline \multirow[t]{8}{*}{ Gradativos } & \multirow{8}{*}{$\begin{array}{l}29 \\
(8,9 \%)\end{array}$} & ultra- & 8 & ultraveloz \\
\hline & & hiper- & 7 & hipertaquillero -ra \\
\hline & & super & 6 & superboyante \\
\hline & & sobre- & 3 & sobredotado -da \\
\hline & & $\mathrm{CO}-$ & 2 & cotitular \\
\hline & & archi- & 1 & archifamoso -sa \\
\hline & & vice- & 1 & viceprimero -ra \\
\hline & & cuasi- & 1 & cuasirreligioso -a \\
\hline \multirow[t]{3}{*}{ Negativos } & \multirow{3}{*}{$\begin{array}{l}12 \\
(3,6 \%)\end{array}$} & des- & 7 & desacomplejado -da \\
\hline & & in- & 3 & incuadrable \\
\hline & & a- & 2 & apartidista \\
\hline \multirow{3}{*}{$\begin{array}{l}\text { De orientación y } \\
\text { disposición }\end{array}$} & \multirow{3}{*}{$\begin{array}{l}90 \\
(27,7 \%)\end{array}$} & anti- & 73 & anticonvulsionante \\
\hline & & pro- & 15 & proamnistía \\
\hline & & contra- & 2 & contraincendios \\
\hline Aspectuales & $\begin{array}{l}10 \\
(3,1 \%)\end{array}$ & re- & 10 & rehumanizador -ora \\
\hline
\end{tabular}

\subsubsection{Prefijación: ¿Mecanismo suficiente para adjetivar?}

La creación de neologismos mediante prefijación es un proceso que tradicionalmente no se ha considerado generador de adjetivos. Varela Ortega (2005: 64) dice que hay que considerar a estas unidades, cuando acompañan a un sustantivo, como "nombres en aposición al nombre núcleo del sintagma". Por su parte, Casado Velarde (2015: 47) considera la afijación de prefijos como un "proceso de creación léxica tautocategorial", así que sí que admite, al menos, la creación de adjetivos a partir de adjetivos ya existentes. A la vista de los datos recogidos, observamos varios fenómenos que pueden enriquecer la visión de la prefijación como mecanismo 
adjetivador: en primer lugar, confirmamos el peso del carácter tautocategorial señalado por Casado Velarde (2015): observamos que 234 de los neologismos recopilados (un $72 \%$ del total de prefijados) también cuentan con sufijos claramente adjetivales, y en todos ellos es fácil inferir que la sufijación fue anterior a la prefijación:

(10)'En 72 horas se realizaron un total de 94 trasplantes: cuatro de ellos bipulmonares (...).' (El Norte de Castilla, 1/1/2012)

(11) 'Los activistas prosaharauis a los que Marruecos impidió bajar del barco (...).' (Diario de León, 1/11/2010)

De la inexistencia de *bipulmón y *prosahara como sustantivos deducimos con facilidad que son los prefijos los que han generado las nuevas unidades. Sin embargo, existe un significativo $28 \%$ del total de prefijados (91 ocurrencias) en los que la etiqueta de adjetivo ha sido asignada a unidades sin sufijos adjetivales:

(12) 'Han estado viendo el funcionamiento del operativo antiincendios' (Diario Palentino, 21/04/2009)

(13) 'Es la primera fase de una operación multifase en una campaña muy compleja.' (La Opinión de Zamora, 21/03/2011)

Si atendemos únicamente los aspectos formales de las unidades recogidas en los ejemplos anteriores, concluiremos, al igual que Varela Ortega (2005), que no estamos frente a adjetivos, ya que en ningún caso concuerdan en género o número con el sustantivo al que acompañan y se pueden interpretar como nombres en aposición, lo que confirmaría el carácter tautocategorial de la prefijación reseñado por Casado Velarde (2015). Sin embargo, la gran diversidad de procedimientos de creación neológica que vamos constatando nos llevan a aventurar que, aparte del criterio morfosintáctico, es necesario no perder de vista la función de este tipo de unidades: en todos los casos recopilados se trata de unidades que, como cualquier adjetivo, “expresan cualidades de los sustantivos a los que acompañan” (Gómez Torrego, 2007: 90) y "se caracterizan por su función de acompañantes de los sustantivos" (Seco, 1989: 164). Cumplen, por tanto, una función claramente descriptiva, subordinada a la del núcleo del sintagma nominal en el que se ven incluidos. Además, no podemos pasar por alto el peso de las características morfosintácticas de otras lenguas con una influencia creciente en el castellano. En concreto, el inglés, código del que no solo se importan unidades, sino también patrones sintácticos, semánticos y discursivos. La ausencia de flexión adjetival, tanto de género como de número, en unidades que describen a sustantivos de los que son adyacentes, podría ser uno de ellos, así como la conversión gramatical de unidades léxicas sin que haya cambios formales de por medio. 
Por último, otro factor que nos lleva a sugerir que la prefijación puede entenderse como mecanismo transcategorizador es la existencia de casos en nuestro estudio en los que dos unidades son completamente equivalentes e intercambiables, con la salvedad de que una de las variantes tiene sufijación adjetival y la otra no, como vemos en la Tabla 6:

Tabla 6. Dobletes de adjetivos intercambiables con y sin sufijación adjetival.

\begin{tabular}{|l|l|}
\hline \multicolumn{1}{|c|}{ Sin sufijación adjetival } & \multicolumn{1}{c|}{ Con sufijación adjetival } \\
\hline $\begin{array}{l}\text { Aunque en } 2009 \text { el número de donantes de } \\
\text { órganos ha descendido en la provincia, hay que } \\
\text { tener en cuenta que fueron donaciones } \\
\text { multiórgano, (El Adelantado de Segovia, } \\
21 / 3 / 2010)\end{array}$ & $\begin{array}{l}\text { La muerte le sobrevino por un fallo } \\
\text { multiorgánico y una parada cardiorrespiratoria. } \\
\text { (El Adelantado de Segovia, 22/4/2010) }\end{array}$ \\
\hline $\begin{array}{l}\text { Durante junio de 2011, el indicador ha pasado del } \\
2,137 \% \text { hasta el 2,162\% marcado hoy en su } \\
\text { cotización intradía. (La Opinión de Zamora, } \\
1 / 7 / 2011)\end{array}$ & $\begin{array}{l}\text { Este operador gestiona de manera integrada } \\
\text { los mercados (diarios e intradiarios) para toda } \\
\text { la Península Ibérica. (La Opinión de Zamora, } \\
1 / 4 / 2014)\end{array}$ \\
\hline $\begin{array}{l}\text { Apúntate a nuestro torneo interempresarial de } \\
\text { Pádel. (El Norte de Castilla, 1/3/2010) }\end{array}$ & $\begin{array}{l}\text { Las ganadoras de categoría A del torneo } \\
\text { interempresas fueron agasajadas con un bono } \\
\text { de belleza. (El Norte de Castilla, 11/7/2011) }\end{array}$ \\
\hline
\end{tabular}

Los ejemplos anteriores muestran tres parejas de unidades intercambiables, de lo que se desprende que funcionalmente, son completamente equivalentes. De hecho, en el caso de 'interempresarial/interempresas' ambas variantes modifican exactamente al mismo sustantivo. Si bien es cierto que la intercambiabilidad de los ejemplos se relativiza por posibles sintagmas anclados con significado propio específico ('fallo multiorgánico', 'cotización intradía'), estamos ante un caso de coexistencia de variantes léxicas de significado similar, y con unas funciones que en todo caso son eminentemente descriptivas. La equivalencia funcional de las variantes nos hace considerar a la formada solo por prefijación como adjetival y, en consecuencia, nos lleva a tomar la prefijación como un mecanismo suficiente para la formación de adjetivos, sin necesidad de tener que contar con una sufijación adjetival previa.

\subsubsection{Relación entre el significado del prefijo y su suficiencia transcategorizadora}

Con el fin de intentar apuntar a alguna causa que provoque la creación de unidades con valor adjetival mediante la mera prefijación de formantes a sustantivos, resulta interesante contrastar el significado de los prefijos empleados y la medida en que toman parte en procesos transcategorizadores o no. Tal y como afirma Feliú Arquiola (2002: 31):

“el comportamiento sintáctico de algunas palabras derivadas se encuentra fuertemente condicionado por las características léxicosemánticas de las bases de las que proceden." 
Del mismo modo, Serrano Dolader (2002: 445) también hace referencia a la "capacidad transcategorizadora de algunos prefijos". La Tabla 7 presenta la proporción de adjetivos formados por prefijación con y sin sufijación previa, para cada tipo de prefijo recogido en la Tabla 7.

Tabla 7. Neologismos adjetivales prefijados con y sin sufijación previa, según el tipo de prefijo.

\begin{tabular}{|l|l|l|l|l|l|}
\hline Tipo de prefijo & Ocurrencias & \multicolumn{2}{|c|}{ Sin sufijación previa } & \multicolumn{2}{c|}{ Con sufijación previa } \\
\hline De orientación & 90 & $47(52 \%)$ & anticrisis & $43(48 \%)$ & proatómico -ca \\
\hline Espaciales & 72 & $20(28 \%)$ & sub 21 & $52(72 \%)$ & subdural \\
\hline Cuantitativos & 77 & $19(24,3 \%)$ & multifase & $58(75,7 \%)$ & semioficial \\
\hline Temporales & 35 & $4(11,5 \%)$ & postpunk & $31(88,5 \%)$ & prelaboral \\
\hline Gradativos & 29 & $0(0 \%)$ & - & $29(100 \%)$ & archifamoso -sa \\
\hline Negativos & 12 & $0(0 \%)$ & - & $12(100 \%)$ & intragable \\
\hline Aspectuales & 10 & $0(0 \%)$ & - & $10(100 \%)$ & reutilizable \\
\hline
\end{tabular}

A tenor de los datos recogidos, y a pesar de las limitaciones de nuestro estudio, no parece desencaminado sugerir que los adjetivos cuyos prefijos tiene un significado relacionado con la orientación y la disposición son mucho más proclives a carecer de sufijación adjetival. De hecho, es la única categoría (y la más numerosa) en la que han aparecido más casos sin sufijación que con ella (52\%). Serrano Dolader (2002) ya apuntó al peso de este tipo de unidades, al presentar el prefijo 'anti-' como ejemplo ‘emblemático’ de este tipo de formantes.

La prefijación, en este caso, es un mecanismo cuya suficiencia transcategorizadora es más patente que en adjetivos de otros tipos. La ausencia total de ejemplos gradativos, negativos o aspectuales terminan por situar este fenómeno como subordinado y secundario al hablar de este tipo de creación de unidades. Además, y tal y como dice Serrano Dolader (2002: 451):

"si se aceptara que estas formaciones sí son adjetivos, habría que determinar cómo inciden los supuestos prefijos en la aparente recategorización adjetiva de una base sustantiva".

Aun así, y a la vista de lo expuesto, no se puede pasar por alto el valor de los prefijos (especialmente los de orientación, pero también los espaciales o los cuantitativos) como partículas capaces per se de crear unidades con funciones que se corresponden de manera muy definida con las normalmente atribuidas a los adjetivos.

\subsection{Composición}

Para hablar de los adjetivos formados por composición (de los que hemos analizado sólo los monoléxicos, dejando a un lado los compuestos sintagmáticos), hemos decidido dividirlos entre los compuestos patrimoniales y los cultos, debido a que los procesos poco frecuentes detectados estaban íntimamente relacionados con esta división. La división entre compuestos patrimoniales y cultos responde a los 
criterios comunes para todos los observatorios de neología de la red NEOROC (OBNEO, 2004: 14), que establecen que un neologismo por composición culta puede estar formado por una forma prefijada y una sufijada ('biogénico -ca'), una forma prefijada y un radical ('autoexigente) o un radical de la lengua y una forma sufijada ('simpaticoide'). Por otra parte, los neologismos por composición patrimonial, siguiendo también los criterios de OBNEO (2004), serían aquellos formados por dos radicales ('quitahambre'). La cada vez mayor asimilación de los formantes grecolatinos como lexemas propios de la lengua o incluso prefijos hace que esa división se vea cada vez más relativizada, como detallaremos a continuación. No obstante, hemos decidido mantenerla por una cuestión de coherencia metodológica con todo el proceso de detección y clasificación que hemos seguido.

\subsubsection{Composición patrimonial}

Los adjetivos formados por composición patrimonial detectados en nuestro estudio fueron 103, un 6,5\% del total. Con el fin de ordenar las ocurrencias, decidimos organizarlas de acuerdo con la categoría gramatical de los lexemas que las forman, tal y como muestra la Tabla 8. Para ello, nos basamos en la clasificación dada por Casado Velarde (2015) y separando los que no tenían cabida dentro de la misma, que suponen un $8,3 \%$ del total, y entre los que no encontramos ninguna pauta digna de ser reseñada.

Tabla 8. Neologismos adjetivales formados por composición patrimonial.

\begin{tabular}{|c|c|c|c|c|c|c|}
\hline & Estructura & Ocurrencias & $\%$ & Ejemplo & Periódico & Fecha \\
\hline \multirow[t]{4}{*}{$\begin{array}{l}\text { Dentro de la } \\
\text { clasificación } \\
\text { de Casado } \\
\text { Velarde }\end{array}$} & $\begin{array}{l}\text { sustantivo } \\
+\mathrm{i}+ \\
\text { adjetivo }\end{array}$ & 9 & $6,6 \%$ & $\begin{array}{l}\text { 'Para ello buscará una } \\
\text { victoria que sería } \\
\text { histórica para el } \\
\text { conjunto franjirrojo.' }\end{array}$ & $\begin{array}{l}\text { El Norte } \\
\text { de Castilla }\end{array}$ & $11 / 4 / 2012$ \\
\hline & $\begin{array}{l}\text { adjetivo }+ \\
\text { adjetivo }\end{array}$ & 74 & $67,5 \%$ & $\begin{array}{l}\text { 'Los editores de Blackie } \\
\text { Books ven en Pippi } \\
\text { Calzaslargas, a una } \\
\text { miembro de la especie } \\
\text { anarcoinfantil.' }\end{array}$ & $\begin{array}{l}\text { El Norte } \\
\text { de Castilla }\end{array}$ & $11 / 3 / 2012$ \\
\hline & $\begin{array}{l}\text { Verbo }+ \\
\text { Objeto } \\
\text { Directo }\end{array}$ & 14 & $13 \%$ & $\begin{array}{l}\text { 'Esperemos que esta no } \\
\text { sea otra maniobra de } \\
\text { esta empresa } \\
\text { cazasubvenciones para } \\
\text { dar otro palo al } \\
\text { maltrecho herario[sic] } \\
\text { público.' }\end{array}$ & $\begin{array}{l}\text { Diario de } \\
\text { León }\end{array}$ & $21 / 10 / 2010$ \\
\hline & $\begin{array}{l}\text { Adverbio + } \\
\text { adjetivo }\end{array}$ & 0 & - & - & - & - \\
\hline $\begin{array}{l}\text { Fuera de la } \\
\text { clasificación } \\
\text { de Casado } \\
\text { Velarde }\end{array}$ & Otros & 6 & $8,3 \%$ & $\begin{array}{l}\text { 'Turchínov ha } \\
\text { respondido así a la } \\
\text { exigencia del grupo } \\
\text { parlamentario de } \\
\text { aprobar una amnistía } \\
\text { para los participantes en } \\
\text { las protestas }(. . .) \text {, de } \\
\text { mayoría rusohablante' }\end{array}$ & $\begin{array}{l}\text { El Norte } \\
\text { de Castilla }\end{array}$ & $10 / 4 / 2014$ \\
\hline
\end{tabular}




\subsubsection{Composición culta}

Como ya adelantábamos al inicio de este apartado, este proceso de formación ha planteado problemas clasificatorios a lo largo de todo nuestro análisis, debido a la detección de formantes en un estadio intermedio entre el prefijo y el formante culto. En consecuencia, nos ha resultado difícil delimitar de manera inequívoca el grado de ‘patrimonialización' de ciertos formantes. ¿Debe seguir considerándose composición culta aquella en la que el formante ya no procede directamente de un elemento grecolatino, sino de una unidad léxica patrimonial ya asentada, como sucede, por ejemplo, en 'fotoperiodista', donde 'foto-' ya no está directamente relacionada con la raíz clásica que significa 'luz', sino con la palabra 'fotografía'?

El enfoque de esta cuestión se presta a múltiples interpretaciones: Sager (1990: 93) alude a "la gran ventaja de la estabilidad formal", al tratarse de elementos procedentes de lenguas muertas, como factor relevante para tomar a estos formantes como "cultos". Adelstein (1998: 2) denomina "formantes cultos asimilados" a los elementos que, a pesar de su clara raíz clásica, tienen más que ver con los procesos prefijativos que con los compositivos, y llama "banalización" al proceso que lleva a un formante a originar unidades derivadas y no compuestas. A este respecto, la autora también señala que "cabe preguntarse si se trata realmente de compuestos híbridos y si el significado de los formantes es el mismo en todos los casos". Por su parte, García Palacios (2001: 2) habla de "elementos compositivos prefijales" y los define como formantes:

"propios de las lenguas actuales que, aunque sean homógrafos del formante culto, no pueden ser confundidos con él, ya que se trata de elementos surgidos del acortamiento de la forma patrimonial, compuesta, que sí que incluía el tema de composición de origen culto" (García Palacios, 2001: 34).

Varela Ortega (2005) hace referencia a criterios formales, como la autonomía léxica de los formantes, su nivel de relevancia o el grado de subordinación que se establece entre ellos, como elementos que pueden ayudar a trazar una línea divisoria consistente. Tampoco podemos pasar por alto un factor reseñado por Guerrero Ramos y Pérez Lagos (2009: 66), quienes, al hablar de este procedimiento, mencionan la facilidad con la que el hablante: "puede acudir a sus componentes creadores y, tomando uno de ellos, construye sus nuevas palabras del lenguaje común uniéndolos a voces tradicionales". Por último, Casado Velarde (2015: 58-59) incluye este tipo de unidades en "los compuestos léxicos propios" (es decir, patrimoniales), aunque les confiere cierta entidad "en la medida en que representan focos de irradiación de algunos temas cultos o asimilados". Por nuestra parte, y teniendo muy en cuenta este fenómeno, como veremos a continuación, entendemos la composición culta (o 'neoclásica', como la denomina Casado Velarde, 2015) como el proceso de creación de nuevas unidades 
en el que entran en juego formantes de raíz grecolatina que, a pesar de no ser entidades totalmente autónomas, gozan de cierta entidad semántica y formal.

Nos encontramos ante un proceso marcado por la productividad, la estabilidad formal y la naturalidad con la que los hablantes lo asumen y utilizan. Concluimos, pues, que el factor desestabilizador tiene que ver con la transferencia de los significados que articulan este tipo de formantes. Éste es el motivo que nos lleva, llegados a este apartado, a tener en cuenta motivos meramente semánticos para analizar la acuñación de adjetivos por composición culta. Consideramos que puede ser un buen punto de partida para tratar el problema de la indefinición entre composición culta y prefijación que presentamos a continuación. Teniendo en cuenta el grado de transferencia de significado del formante clásico original a los neologismos adjetivales detectados, hemos agrupado estos en tres categorías:

\subsubsection{Unidades en los que se conserva el significado original del formante culto}

Estas unidades encarnan la composición culta en su sentido más canónico: observamos con claridad que un formante clásico con un significado estable y bien delimitado se une a otra base léxica. Encontramos casos en los que la base léxica propia está después del formante culto y casos en los que está antes. Normalmente tienen un matiz de especialización temática, incluso en contextos de registros coloquiales o divulgativos, como son lo que podemos encontrar en medios de prensa escrita:

(14) 'El cemento es un tejido ubicado entre el hueso y la encía que suele desaparecer en las enfermedades periodontales.' (El Norte de Castilla, 1/3/2011)

(15) 'La artillería republicana lanzó 200 proyectiles que contenían (...) gases estornudógenos y lacrimógenos.' (Diario de Burgos, 1/4/2014)

\subsubsection{Truncamiento de una unidad previa y resemantización del formante culto}

Esta categoría engloba los casos en los que el significado original del formante clásico se pierde y éste pasa a ser más un truncamiento de una palabra ya existente que se añade a otra base léxica. En la mayoría de estos casos la resemantización es clara y se adivina con facilidad el truncamiento que precede a su formación:

(16) 'Ortiz apela a la concienciación de unos y otros para que este transporte ecosostenible tenga más cabida en una ciudad ideal,' (El Norte de Castilla, $21 / 10 / 2010)$

(17) 'En otros países, parte de la abstención es euroescéptica. En España es más euroindiferente que realmente contraria.' (Diario Palentino, 1/6/2009)

En el caso de 'ecosostenible', el significado de 'casa' del oikos griego original resulta totalmente opaco y, en su lugar la referencia semántica remite a 'ecología'. Por 
su parte, el 'euro-' de 'euroindiferente' no hace referencia al continente europeo, sino a la Unión Europea. Ambos son ejemplos de la estabilidad y la productividad a la que hacían referencia Sager (1990) y Guerrero Ramos y Pérez Lagos (2009).

\subsubsection{Formantes homónimos}

Frente a la conservación y a la reasimilación que acabamos de reseñar, nos ha llamado la atención encontrar casos de adjetivos diferentes formados mediante parejas de formantes homónimos que remitían, en unos casos al significado original clásico y en otros al significado adquirido de una unidad compuesta propia preexistente. Los formantes 'cardio'- y 'bio-' ilustran con claridad este fenómeno, tal y como vemos en la Tabla 9:

Tabla 9. Composición culta adjetival. Formantes homónimos.

\begin{tabular}{|l|l|l|}
\hline Formante & \multicolumn{1}{|c|}{$\begin{array}{c}\text { Conservación del significado } \\
\text { original }\end{array}$} & \multicolumn{1}{c|}{ Truncamiento y resemantización } \\
\hline cardio- & $\begin{array}{l}\text { La aplicación ayuda a prepararse para } \\
\text { actuar ante una parada } \\
\text { cardiopulmonar. (El Norte de } \\
\text { Castilla, 1/05/2013) }\end{array}$ & $\begin{array}{l}\text { La Agrupación (...) lamenta que esta decisión } \\
\text { llegue con tanto retraso, después de que hace } \\
\text { cinco años presentaran un proyecto para crear } \\
\text { una ciudad cardioprotegida. (El Norte de } \\
\text { Castilla, 21/11/2010) }\end{array}$ \\
\hline bio- & $\begin{array}{l}\text { El título de Criminología «cuenta con } \\
\text { gran demanda», mientras que } \\
\text { Farmacia permitiría potenciar la oferta } \\
\text { biosanitaria. (El Norte de Castilla, } \\
2 / 02 / 2011)\end{array}$ & $\begin{array}{l}\text { Limpieza con eliminación de restos orgánicos, } \\
\text { y eflorescencias y posterior tratamiento } \\
\text { biocida, (...). (El Adelantado de Segovia, } \\
1 / 08 / 2010)\end{array}$ \\
\hline
\end{tabular}

Como vemos en los contextos de la Tabla 9, un mismo formante culto puede tener distintas realizaciones en la acuñación de nuevas unidades: de mientras que 'cardioprotegido - da' procede del truncamiento de 'cardiopatía' y sirve pare describir, en el contexto encontrado, a una ciudad que protege a sus habitantes de los problemas de salud relacionados con el corazón, la referencia a 'corazón' del 'cardio-' de 'cardiopulmonar' resulta mucho más nítida. Por su parte, el formante 'bio-' en 'biosanitario -a' está relacionado con 'biología', mientras que en 'biocida' remite directamente al significado original de 'vida' del formante.

Es en este estado intermedio de convivencia entre unidades, en las que el elemento grecolatino es más o menos claro, donde se encuentra la singularidad de este tipo de adjetivos: demuestran que los procesos de formación neológica, y en concreto aquellos en los que se importan unidades de otros códigos, son un continuum cuyas fases pueden verse solapadas, tal y como refleja la Figura 1. 


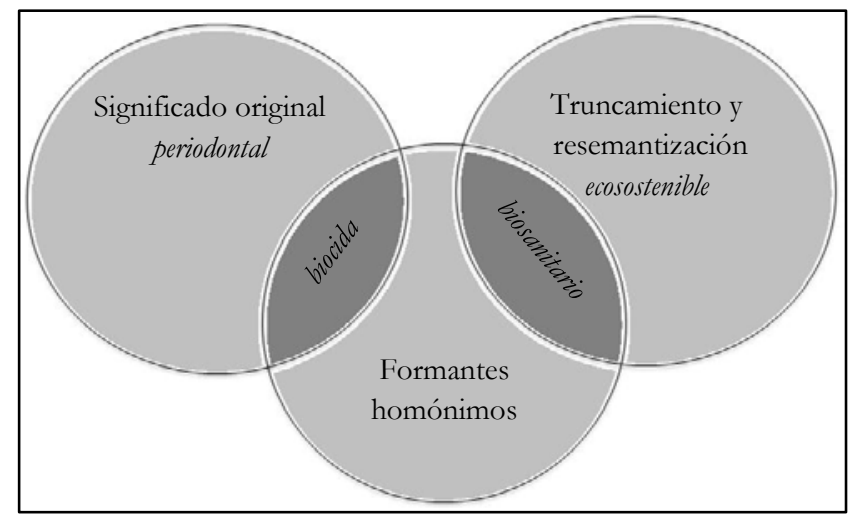

Figura 1. Comportamiento de los formantes en la creación de adjetivos por composición culta.

\section{Discusión}

El hecho de haber dejado de lado las ocurrencias léxicas puntuales nos ha permitido definir ciertos procesos recurrentes, dentro de la irregularidad constatada. En el caso de los neologismos por sufijación, el esquema es claro: en todos los casos reseñados se produce una modificación del significado de las unidades mediante la utilización de estrategias y elementos comunes y asentados en la lengua, pero dando respuesta a nuevas necesidades denominativas. En el caso de la prefijación y de la composición, la pauta es ligeramente distinta, ya que no es únicamente la estructura morfosemántica de las unidades lo que las hace especiales, sino que su carácter adjetival también se debe a las particularidades de las funciones que desempeñan en los contextos en los que han sido detectadas.

Se ha constatado una influencia nada desdeñable de mecanismos neológicos más propios de la lengua inglesa: prueba de ello es la conversión de unidades con estructura nominal en neologismos con valor adjetival que no concuerdan en número y género con los sustantivos a los que acompañan. De alguna manera, los datos compilados apuntan a que la dependencia del inglés en el plano léxico va más allá de la mera importación de unidades con mayor o menor grado de inclusión en la lengua, y que pasa por la adopción de estrategias menos evidentes que condicionan la manera en que se acuñan nuevas palabras.

A la luz de lo observado, podemos hablar de tres fenómenos relevantes en los nuevos procesos de formación adjetival que hemos apuntado, que pueden dar pie a futuros estudios más específicos:

- La analogía: en el caso de los adjetivos formados por sufijación, este fenómeno, entendido como "la creación de una o varias unidades léxicas a partir del modelo ofrecido por otra(s) unidad(es) que establecen con la(s) nueva(s) una determinada relación semántica y/o formal" (Martín Camacho, 2007: 177) desempeña un papel reseñable en los procesos analizados. No nos hemos 
adentrado en la cuestión, pero es probable que las unidades incluidas en nuestro estudio con un mayor grado de estabilidad y difusión propicien la aparición de otras similares y originen las irregularidades recurrentes explicadas.

- El registro de uso: a tenor de lo detectado en el caso de la sufijación -(ist)ico/(ist)ica, como incentivo a la creatividad adjetival, permitiendo la aparición de parejas de unidades adjetivas sinónimas (material/matérico -ca, ornamental/ornamentístico -ca) en las que una se adecúa más a un registro más elevado.

- La prefijación: resulta ser relevante como hipotético proceso transcategorizador que incentiva la creación de adjetivos. Asimismo, también es significativo que prefijos con determinados significados provoquen ese cambio de categoría gramatical con más frecuencia que otros.

\section{CONCLUSIONES}

Los datos que presentamos en este trabajo nos hacen pensar en la contraposición entre las posibilidades de realización morfológicas de cada código y la lexicalización de sus distintos elementos (Sablayrolles, 2010) que, en última instancia, son un trasunto del choque que se produce entre la creatividad de los hablantes y la tendencia a la convención (Casado Velarde, 2015) a la hora de denominar nuevas cualidades.

En definitiva, confirmamos que, a tenor de los datos encontrados en nuestro corpus, la neología adjetival dista mucho de ser previsible y estable, y que, como ya dijo Pena (1999) (citado en Bosque \& Demonte, 1999: 4311) es necesario "acudir también a las propiedades sintácticas o combinatorias de la palabra e incluso a determinadas características de tipo semántico" puesto que "las propiedades formales internas no son suficientes para definir la totalidad de clases de palabras". Sugerimos, pues, tener en cuenta elementos como la influencia del inglés o el peso de las funciones sintácticas para estudiar la hipotética naturaleza adjetival de aquellos neologismos que se utilicen para completar el significado de los sustantivos. Concluimos que la neología adjetival puede ajustarse a patrones que se escapan de las clasificaciones tradicionales, y es capaz de actuar como acicate creativo para la regeneración léxica de los códigos.

\section{REFERENCIAS BIBLIOGRÁFICAS}

Adelstein, A. (1998). Banalización de términos con formantes de origen grecolatino. En Red Iberoamericana de Terminología (Ed.), $V$ Simposio Iberoamericano de Terminologia-Riterm (pp. 12-17). México: Riterm.

Álvarez Catalá, S. (2010). El estado del arte de la terminología y la neología en Uruguay. Montevideo: Unión Latina.

Bardin, B., Lefevère, G., Marcellesi C. \& Mortureux, M. Fr. (1974). À propos du sentiment néologique. Langages, la néologie lexicale, 36, 45-52. 
Battaner, M. (Dir.) (2001). Lema. Diccionario de Lengua Española VOX. Barcelona: Spes Editorial.

Berri, M. \& Borhn, A. (2009). La neología en el ámbito de la música: La formación de nombres y adjetivos en -ero e -ista. Debate Terminológico, 5.

Bosque, I. \& Demonte, V. (1999). Gramática descriptiva de la lengua española. Madrid: Espasa.

Boulanger, J. C. (2010). Sur l'existence des concepts de néologie et de néologisme Propos sur un paradoxe lexical et historique. En Actes del I congrès internacional de neologia de les llengües romàniques (pp. 31-74). Barcelona: IULA Universitat Pompeu Fabra.

Cabré, M. T. (2000). La neologia com a mesura de la vitalitat interna de les llengües. En M. T. Cabré, J. Freixa, J. \& E. Solé (Eds.), I seminari de Neologia (pp. 85108). Barcelona: IULA, Universitat Pompeu Fabra.

Casado Velarde, M. (2015). La innovación léxica en el español actual. Madrid: Síntesis.

de Miguel, E. (1986). Papeles temáticos y regla de formación de adjetivos enble. Dicenda. Cuadernos de Filología Hispánica, 5, 159-183.

Feliú Arquiola, E. (2002). La opacidad sintáctica de las palabras derivadas: Una nueva perspectiva. Estudios de Lingüística de la Universidad de Alicante, 16, 273-294.

Freixa, J. (2010). Paraules amb rareses. Terminàlia, 1(1), 7-16.

Fuentes, M., Cañete, P., Gerding, C., Kotz, G. \& Pecchi, A. (2010). Productividad del sufijo-ero en la neología del español de Argentina, Chile y Uruguay. Revista Signos. Estudios de Lingüística, 43(72), 49-69.

García Palacios, J. (2001). La quimera del euro-. Acerca de algunos elementos compositivos en español. Revista de Lexicografía, 7, 33-62.

Gómez Torrego, L. (2007). Análisis morfológico. Teoría y práctica. Madrid: Ediciones SM.

Guerrero Ramos, G. \& Lagos Pérez, F. P. (2009). La composición culta y la neología de la prensa escrita. Revista de Investigación Lingüistica, 12, 65-81.

Guespin, L. (1974). Néologie et énonciation: Problèmes théoriques et méthodologiques. Langages, 36, 74-82

Guilbert, L. (1975). La créativité lexicale. París: Larousse.

Kornfeld, L. (2014). Adjetivos derivados y cuantificación: La herencia de rasgos aspectuales en español. Revista española de lingüistica, 39(2), 153-176. 
Lang, M. F. (1992). Formación de palabras en español: Morfología derivativa productiva en el léxico moderno. Madrid: Cátedra.

Martín Camacho, J. C. (2007). Observaciones sobre el papel de la analogía en los procesos morfológicos. Revista de Investigación Lingüística, 10, 173-191.

Moreno Benítez, D. (2010). La dimensión argumentativa de los adjetivos relacionales. Tesis doctoral, Universidad de Sevilla, Sevilla, España.

Nazar, R. \& Vidal, V. (2008). Aproximación cuantitativa a la neología. En Actas del I Congreso Internacional de Neología en las lenguas románicas. Barcelona, España.

Observatori de Neología (2004). Metodología del trabajo en neología: Criterios, materiales y procesos. Barcelona: IULA, Universitat Pompeu Fabra.

Pena, J. (1999). Partes de la morfología. Las unidades del análisis morfológico. En I. Bosque \& V. Demonte (Dirs.), Gramática descriptiva de la lengua española (pp. 4305-4366). Madrid: Espasa Calpe.

Pena, J. (2001). Formación de palabras. En M. Avar (Dir.), Introducción a la lingüística española (pp. 235-253). Barcelona: Ariel,

Quirion, J. (2010). Pour des critères extralinguistiques de néologicité. En Actes del I congrès internacional de neologia de les llengües romàniques (pp. 123-126). Barcelona: IULA, Universitat Pompeu Fabra.

Rainer, F. (2003). Semantic fragmentation in word-formation: The case of Spanish azo. En R. Singh \& S. Starosta (Eds.), Explorations in Seamless Morphology. (pp. 197-211). Nueva Dehli: Sage.

Rainer, F. (2010). Sobre la polisemia en la formación de palabras. Hesperia: Anuario de filología hispánica, 13, 7-52.

Real Academia Española. (2001). Diccionario de la Lengua Española. Madrid: Espasa.

Real Academia Española. (2009). Nueva gramática de la Lengua Española. Madrid: Espasa.

Rey, A. (1976). Néologisme: Un pseudo-concept? Cahiers de Lexicologie: Revue Internationale de Lexicologie et Lexicographie, 28, 3-17.

Sablayrolles, J. F. (2009). ¿Neologismo o no? Ensayo de clarificación de algunos problemas de incorporación. Revista de Investigación Lingüística, 12, 1139-1146.

Sablayrolles, J. F. (2010). Néologisme homonymique, néologisme polysémique et évolution de sens. Pour une restriction de la néologie sémantique. En I. M. Alves (Ed.), Neologia e neologismos em diferentes perspectivas (pp. 83-100). Sao Paulo: Paulistana. 
Sager, J. C. (1990). A practical course in terminology processing. Philadelphia: John Benjamins.

Santana, O., Carreras F., Pérez. J. \& Rodríguez, R. (2003). Relaciones morfoléxicas sufijales del español. Procesamiento del Lenguaje Natural, 30, 1-73.

Seco, M. (1989). Gramática esencial del español. Madrid: Espasa Calpe.

Serrano Dolader, D. (2002). Hacia una concepción no-discreta de algunas formaciones con anti- en español. Revista Española de Lingüistica, 32(2), 387-411.

Serrano Dolader, D. (2012). Sobre la didáctica de la formación de palabras: El caso de la prefijación negativa. En E. Montoro del Arco (Ed.), Quaderns de Filologia, Neologia y creatividad lingüistica (pp. 183-215). España: Universitat de València.

Torijano, J. A. \& Sánchez Ibáñez, M. (2013). Gentilicios en la prensa de Castilla y León: ¿Innovación o conservadurismo? Revista de Lexicografía, 19, 167-182.

Vallès, T. (2002). La productividad morfológica en un modelo dinámico basado en el uso y en los usuarios. En M. T. Cabré, J. Freixa \& E. Solé (Eds.), Lexic $i$ Neologia (pp. 139-157). Barcelona: IULA, Universitat Pompeu Fabra.

Varela Ortega, S. (2005). Morfología léxica: La formación de palabras. Madrid: Gredos.

\section{NOTAS}

${ }^{1}$ El presente estudio se ha realizado en el marco del Proyecto de Investigación Mecanismos de generación neológica y actualización léxica del español a través del estudio de la prensa castellanoleonesa (Neousal II). Junta de Castilla y León (con investigadores externos). Ref.: SA274U13.

${ }^{2}$ El Norte de Castilla, El Día de Valladolid, El Diario Palentino, Diario de León. Diario de Burgos, Adelantado de Segovia, La Opinión de Zamora, La Gaceta de Salamanca, Diario de Ávila, El Mundo (Edición Castilla y León). 